\title{
Orexin-1 Receptor Signaling in Ventral Pallidum Regulates Motivation for the Opioid Remifentanil
}

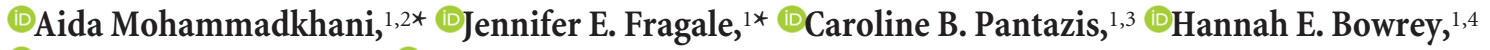 \\ ๑Morgan H. James, ${ }^{1,5}$ and ${ }^{\circledR}$ Gary Aston-Jones ${ }^{1}$ \\ ${ }^{1}$ Brain Health Institute, Rutgers University, Piscataway, New Jersey 08854, ${ }^{2}$ School of Cognitive Sciences (SCS), Institute for Research in Fundamental \\ Sciences (IPM), Tehran, Iran 19395-5746, ${ }^{3}$ Neurobiology of Addiction Section, Integrative Neuroscience Research Branch, National Institute on Drug \\ Abuse, Intramural Research Program, National Institutes of Health, Baltimore, Maryland 21224, ${ }^{4}$ Save Sight Institute, University of Sydney, New South \\ Wales, Australia 2000, and 5Florey Institute of Neuroscience and Mental Health, University of Melbourne, Victoria, Australia 3052
}

Signaling at the orexin-1 receptor (0xR1) is important for motivated drug taking. Using a within-session behavioral economics (BE) procedure, we previously found that pharmacologic blockade of the 0xR1 decreased motivation (increased demand elasticity) for the potent and short-acting opioid remifentanil and reduced low-effort remifentanil consumption. However, the mechanism through which orexin regulates remifentanil demand is currently unknown. Previous work implicated OxR1 signaling within ventral pallidum (VP) as a potential target. VP is densely innervated by orexin fibers and is known to regulate opioid reward. Accordingly, this study sought to determine the role of VP OxR1 signaling in remifentanil demand and cue-induced reinstatement of remifentanil seeking in male rats. Intra-VP microinjections of the OxR1 antagonist SB-334867 (SB) decreased motivation (increased demand elasticity; $\alpha$ ) for remifentanil without affecting remifentanil consumption at low effort. Baseline $\alpha$ values predicted the degree of cue-induced remifentanil seeking, and microinjection of SB into VP attenuated this behavior without affecting extinction responding. Baseline $\alpha$ values also predicted SB efficacy, such that SB was most effective in attenuating reinstatement behavior in highly motivated rats. Together, these findings support a selective role for VP OxR1 signaling in motivation for the opioid remifentanil. Our findings also highlight the utility of BE in predicting relapse propensity and efficacy of treatment with 0xR1 antagonists.

Key words: behavioral economics; opioids; orexin; ventral pallidum

Significance Statement

Abuse of opioids has risen rapidly and continues to be a major health crisis. Thus, there is an urgent need to better understand the neurobiological and behavioral mechanisms underlying opioid addiction. Here, we investigate the role of orexin-1 receptor signaling (OxR1) within ventral pallidum (VP) in remifentanil demand and cue-induced reinstatement of remifentanil seeking. Using a within-session behavioral economics procedure, we show that intra-VP microinjections of the OxR1 antagonist SB-334867 decreased motivation (increased demand elasticity) without affecting remifentanil consumption at low effort. We also found that SB microinjected intra-VP attenuated cue-induced reinstatement of remifentanil seeking. Together, our results support a role for VP OxR1 signaling in opioid reward.

\section{Introduction}

Opioid addiction has become a major health crisis (Compton and Volkow, 2006; Smith et al., 2009; Lewis et al., 2017; Volkow

Received Jan. 7, 2019; revised Sept. 30, 2019; accepted 0ct. 2, 2019.

Author contributions: A.M., M.H.J., and G.A.-J. designed research; A.M. and J.E.F. performed research; A.M., J.E.F., C.B.P., M.H.J., H.E.B., and G.A.-J. analyzed data; A.M. wrote the first draft of the paper; A.M. and M.H.J. wrote the paper; J.E.F., C.B.P., M.H.J., H.E.B., and G.A.-J. edited the paper.

This work was supported by the Institute for Research in Fundamental Sciences (IPM), an Institutional Research and Academic Career Development Award-National Institutes of Health (Postdoctoral Fellowship K12 GM093854), the National Health and Medical Research Council of Australia (C.J. Martin Fellowships 1072706 and 1128089), and the National Institute of Drug Abuse-NIH (Grants F31 DA042588, K99DA045765, and R01 DA006214). We thank and Collins, 2017; Dobbs and Fogger, 2018). A better understanding of the neurobiological mechanisms underlying this disorder is necessary to develop novel clinical treatments. Orexins (hypocretins) are neuropeptides exclusively produced by neurons in the hypothalamus that project broadly throughout the

Kirsten Porter-Stranksy and Brandon Bentzley for assistance with the remifentanil demand protocol and Orion Yedidia for assistance in performing behavioral experiments for this study.

The authors declare no competing financial interests.

*A.M. and J.E.F. contributed equally to this work.

Correspondence should be addressed to Gary Aston-Jones at gsa35@ca.rutgers.edu.

https://doi.org/10.1523/JNEUROSCI.0255-19.2019

Copyright $\odot 2019$ the authors 
central nervous system and regulate a wide range of behaviors including drug seeking (Sakurai et al., 1998a; de Lecea et al., 1998; Harris et al., 2005). Signaling at the OxR1 has been implicated in a variety of drug-seeking behaviors and plays a critical role in opioid addiction (Narita et al., 2006; Sharf et al., 2010; Baimel et al., 2015). We found that stimulation of lateral hypothalamus (LH) orexin neurons reinstated extinguished morphine seeking and that systemic pretreatment with the selective orexin-1 receptor (OxR1) antagonist SB-334867 (SB) blocked this effect (Harris et al., 2005). We also reported that systemic blockade of OxR1s attenuated cue-induced reinstatement of heroin, fentanyl, and remifentanil seeking (Smith and Aston-Jones, 2012; PorterStransky et al., 2017; Fragale et al., 2019). Using within-session behavioral economics (BE) procedures, we recently found that systemic OxR1 antagonism decreased demand for fentanyl and remifentanil (Porter-Stransky et al., 2017; Fragale et al., 2019). Together, these results support a role for OxR1 signaling in opioid addiction. However, the brain sites at which OxR1 signaling regulates opioid reward remain unknown.

Ventral pallidum (VP) represents a potential target for OxR1 signaling in opioid addiction. VP is densely innervated by orexin fibers (Peyron et al., 1998; Baldo et al., 2003) and expresses both OxR1s and OxR2s (Marcus et al., 2001). VP inactivation decreases heroin consumption under high-effort schedules of reinforcement (Hubner and Koob, 1990) and blocks expression of morphine conditioned place preference (Dallimore et al., 2006). Together, these studies suggest a potential role for VP OxR1 signaling in opioid reward.

In the present study, we test the hypothesis that VP OxR1 signaling regulates demand for the ultra-short-acting opioid remifentanil using a within-session BE procedure. We also investigate the role of VP OxR1 signaling in cue-induced reinstatement of remifentanil seeking. The short half-life of remifentanil makes it ideal for within-session BE testing (Glass et al., 1999), and the abuse liability of remifentanil makes it an important opioid to study (Zacny and Galinkin, 1999; Baylon et al., 2000; Panlilio and Schindler, 2000; Levine and Bryson, 2010). We first sought to confirm the results of our previous study, which found that systemic administration of the selective OxR1 antagonist SB reduced remifentanil demand as well as cue-induced remifentanil seeking. We then compared these effects with those after intra-VP microinfusions of SB. In agreement with our previous study, systemic SB reduced motivation (increased demand elasticity; $\alpha$ ) and decreased low effort consumption of remifentanil. In contrast, intra-VP SB decreased motivation without affecting low-effort consumption of remifentanil. Both systemic and intra-VP SB attenuated cue-induced reinstatement of remifentanil seeking. Together, our findings point to a critical role for VP OxR1 signaling in motivation for opioid reward.

\section{Materials and Methods}

Subjects. Male Sprague Dawley rats (275-300 g; Charles River Laboratories) were single-housed and maintained under a $12 \mathrm{~h}$ reverse light/dark cycle (lights off at 08:00 h) in a temperature and humidity-controlled animal facility at Rutgers University. Food and water were available ad libitum. Rats were handled daily after a $3 \mathrm{~d}$ acclimation period to the facility. All experimental procedures were approved by the Rutgers Institutional Animal Care and Use Committee and were conducted according to the National Institutes of Health's Guide for the Care and Use of Laboratory Animals.

Drugs. Remifentanil and the selective OxR1 antagonist SB-334867 (SB) were generously donated by the National Institute of Drug Abuse. Remifentanil was dissolved in $0.9 \%$ sterile saline for intravenous selfadministration. For systemic administration, SB was prepared as de- scribed previously and injected intraperitoneally at a volume of $4.0 \mathrm{ml} / \mathrm{kg}$ (Bentzley and Aston-Jones, 2015; Porter-Stransky et al., 2017; James et al., 2018b, 2019; Fragale et al., 2019). For intra-VP microinjections, SB was dissolved in sterile artificial CSF (aCSF) to a concentration of 0.1, 0.5, and $1 \mathrm{~mm}$, as described previously (Mahler et al., 2013).

Intravenous catheter and stereotaxic surgery. Rats were implanted with indwelling jugular vein catheters, as described previously (Smith et al., 2009). In a subset of rats, bilateral stainless steel guide cannulae (22G, Plastics One) were implanted $2 \mathrm{~mm}$ dorsal to caudal VP $(-0.8 \mathrm{~mm}$ posterior, $\pm 2.6 \mathrm{~mm}$ lateral, $-7.5 \mathrm{~mm}$ ventral, relative to bregma (Paxinos and Watson, 1998). Cannulae were secured to the skull using jeweler's screws and dental acrylic, and stylets were placed into the guide cannula to prevent occlusion. Here, we specifically targeted the caudal subregion of the $\mathrm{VP}(\mathrm{cVP})$ as this region contains the greatest density of orexin fibers (Baldo et al., 2003).

Self-administration training. Self-administration training occurred in Med Associates operant chambers (Med Associates), fitted with 2 levers (active and inactive), a stimulus light located directly above the active lever, speaker, and house light. Operant boxes were housed in individual sound-attenuating chambers, and all boxes were controlled by Med-PC IV software (Med Associates). Self-administration training was performed in $2 \mathrm{~h}$ sessions on a fixed-ratio (FR-1) schedule, as described previously (Porter-Stransky et al., 2017). Briefly, a response on the active lever resulted in a $4 \mathrm{~s}$ infusion of $1 \mu \mathrm{g}$ of intravenous remifentanil, paired with light and tone. Each infusion was followed by a $20 \mathrm{~s}$ time-out signaled by termination of the house light. Responses on the inactive lever had no consequences. Training sessions terminated after $2 \mathrm{~h}$ or $80 \mathrm{infu}-$ sions, whichever occurred first. Rats were trained for a minimum of six sessions and to a criterion of $>25$ infusions for three consecutive sessions.

$B E$ procedure. Remifentanil demand was assessed using a withinsession BE procedure, as described previously (Porter-Stransky et al., 2017). Briefly, rats were tested in 110 min sessions where the dose of remifentanil per infusion was decreased in successive $10 \mathrm{~min}$ bins on a quarter logarithmic scale $(2,1,0.6,0.3,0.2,0.10 .06,0.03,0.02,0.01$, and $0.006 \mu \mathrm{g} /$ infusion). Each infusion was paired with light and tone, and responses on the inactive lever were not reinforced. Unlike FR-1 selfadministration training, timeout periods did not follow infusions.

Demand curves were fit to the data for each session for individual subjects using the exponential demand equation and least sum of squares approach (Hursh and Silberberg, 2008), as described previously (Bentzley et al., 2013, 2014; Porter-Stransky et al., 2017). Demand parameters $Q_{0}$ and $\alpha$ were assessed. $Q_{0}$ depicts the theoretical consumption of drug when no effort is required and $\alpha$ is a measure of demand elasticity (price sensitivity of consumption) and is an inverse measure of motivation (Hursh and Silberberg, 2008). Rats were trained for a minimum of $6 \mathrm{~d}$ and until stable demand was observed before any pharmacological manipulation. Animals were considered stable when demand parameters ( $Q_{0}$ and $\alpha$ values) varied by $<25 \%$ across three consecutive sessions. Rats were given a minimum of $3 \mathrm{~d}$ between testing to ensure a return to baseline demand.

Extinction and cue-induced reinstatement. Rats were exposed to $2 \mathrm{~h}$ extinction sessions during which responses on the active lever were no longer reinforced (no infusion or cues). Rats were trained for a minimum of seven sessions and until responding in the last three sessions was $\leq 25$ presses. During reinstatement tests, presses on the active lever were paired with remifentanil-associated cues (light and tone). Rats received at least two extinction sessions with responding $\leq 25$ presses between reinstatement tests.

Systemic injections. A subset of rats received intraperitoneal injections of vehicle or $\mathrm{SB}(30 \mathrm{mg} / \mathrm{kg}) 30 \mathrm{~min}$ before $\mathrm{BE}$ testing and cue-induced reinstatement in a counterbalanced design. $\mathrm{SB}(30 \mathrm{mg} / \mathrm{kg})$ was tested as lower doses of SB $(10 \mathrm{mg} / \mathrm{kg})$ were previously found to be ineffective at altering remifentanil demand and reinstatement (Porter-Stransky et al., 2017).

Dorsal control and VP microinfusions. Intra-VP microinjections were performed in a separate group of rats. Control microinjections of SB (1.0 $\mathrm{mM}$; highest concentration microinfused into VP) were first performed $1.8 \mathrm{~mm}$ dorsal to VP $(0.2 \mathrm{~mm}$ below the tip of the guide cannula) to 
A

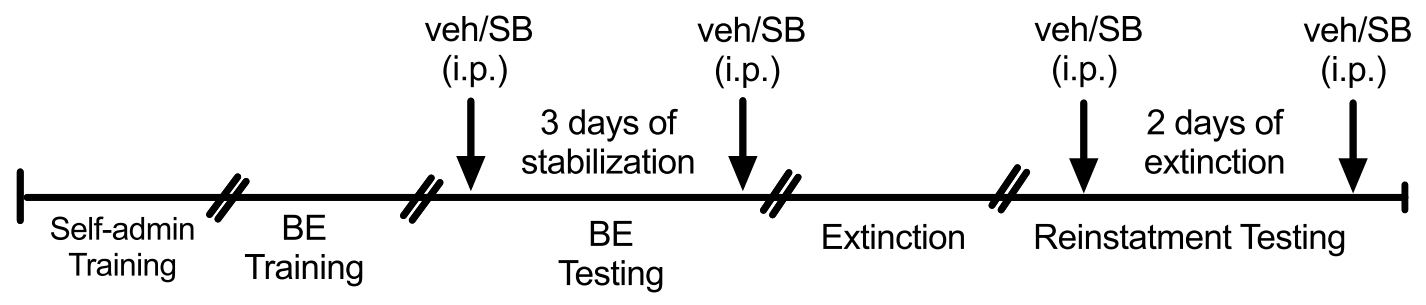

B

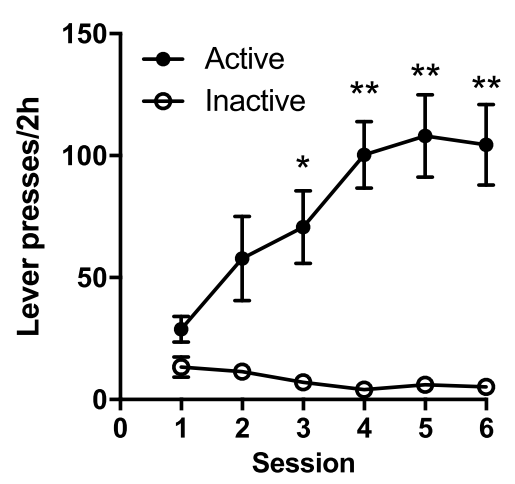

E

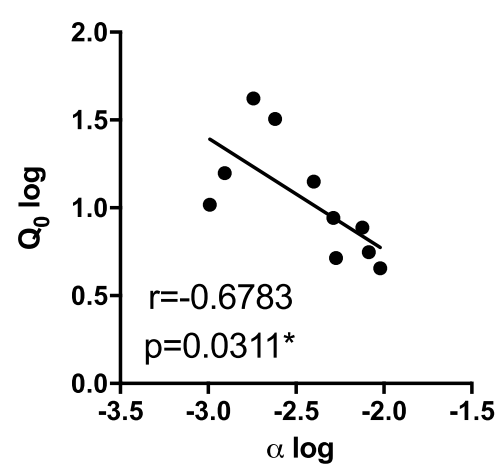

H

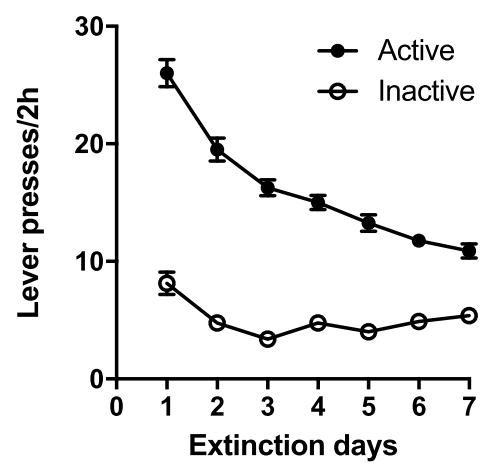

C

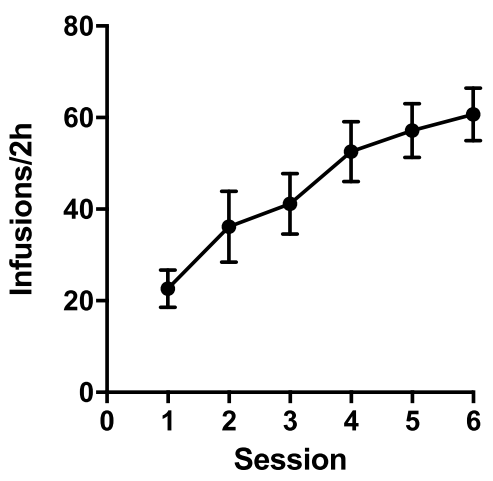

$\mathbf{F}$

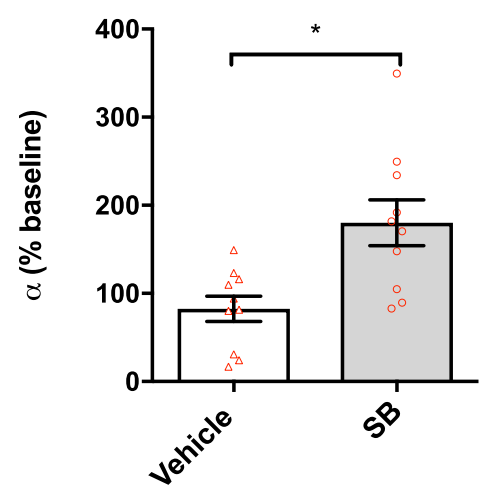

I

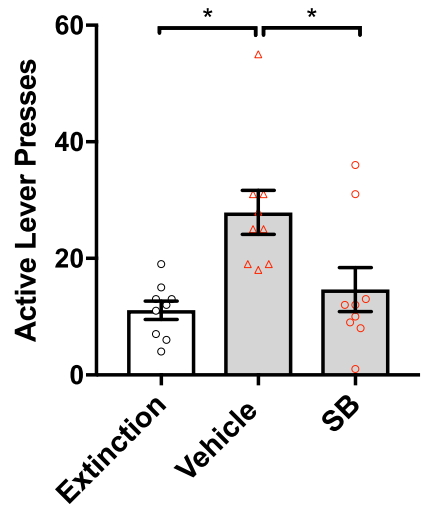

D

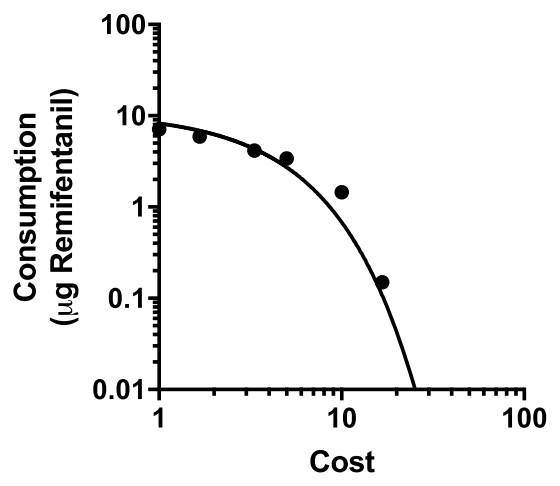

(Response/ug Remifentanil)

G

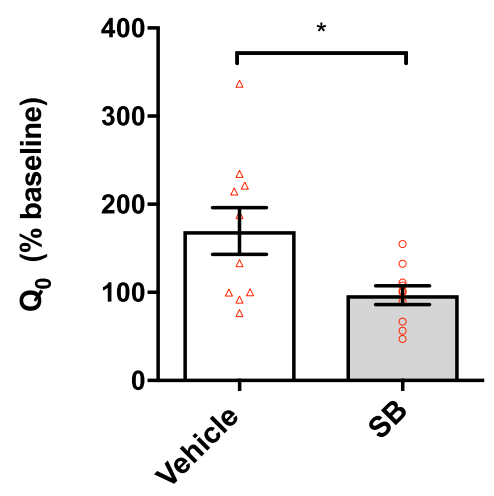

J

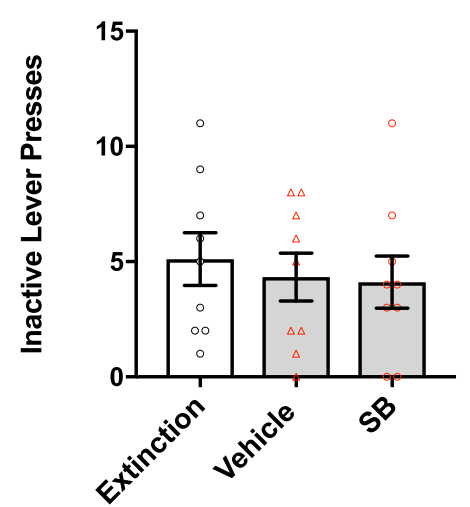

Figure 1. Effect of systemic $0 x R 1$ blockade on demand and reinstatement for remifentanil. $A$, Timeline for behavioral training and testing. B, Active and inactive lever responding on the final $6 \mathrm{~d}$ of FR1 self-administration training. Rats $(n=11)$ readily learned to discriminate between the active and inactive levers and made significantly more active vs inactive lever presses across the final 4 self-administration sessions (mixed-design ANOVA with Bonferroni comparison; ${ }^{*} p<0.05,{ }^{* *} p<0.001$ ). C, Number of remifentanil infusions earned across the final $6 \mathrm{~d}$ of FR1 self-administration training. A significant escalation of intake was observed across training ( $r$ m-ANOVA; $p=0.0003$ ). $\boldsymbol{D}$, After self-administration training, rats $(n=10)$ were trained and tested on a within-session BE procedure. Figure depicts a representative demand curve for a single animal during a remifentanil BE session. $\boldsymbol{E}$, Baseline $Q_{0}$ (intake at null cost) and $\alpha$ (demand elasticity) values of each animal were negatively correlated (linear regression; $p=0.031) . F$, When administered before BE testing, SB (30 mg/kg, i.p.) increased demand (Figure legend continues.) 
confirm that behavior changes with intra-VP injections were not due to diffusion of SB along the cannula tract. Mock microinjections were performed $24 \mathrm{~h}$ before initial intra-VP microinjections by inserting bilateral injectors (28G) into VP (2 mm below the guide cannulae) and keeping the injectors in place for $1 \mathrm{~min}$. To determine the effects of intra-VP SB on remifentanil demand, rats received microinfusions of $0.3 \mu \mathrm{l} /$ side aCSF or SB $(0.1,0.5$, or $1.0 \mathrm{~mm}) 5$ min before BE tests. Different SB concentrations were assessed in separate groups of rats; this was done to limit the number of repeated microinfusions per site. In addition to SB, all groups received aCSF control infusions (counterbalanced). Dorsal control injections were only performed in rats that received $1.0 \mathrm{~mm}$ intra-VP SB.

To test the effects of intra-VP SB on cue-induced reinstatement of remifentanil seeking, rats received microinfusions of $0.3 \mu \mathrm{l} /$ side aCSF or $\mathrm{SB}(0.5$, and $1.0 \mathrm{~mm}) 5 \mathrm{~min}$ before reinstatement tests. Again, separate groups of rats were used to test each dose. To test for nonspecific effects of the injection on responding, a separate group of rats also received intra-VP aCSF or SB 5 min before an extinction session (betweensubjects design). These tests took place after a minimum of seven extinction sessions, and after the number of active lever responses was $\leq 25$ presses and differed by $<25 \%$ across three consecutive sessions. After testing, these rats received three additional extinction sessions before reinstatement testing.

All microinfusions took place over $70 \mathrm{~s}$ and injectors were left in place for $1 \mathrm{~min}$ after infusions to limit backflow of the injectate. Microinfusions were administered via polyethylene tubing connected to gastight 10 $\mu$ l Hamilton syringes set in an infusion pump (model 975, Harvard Apparatus). SB doses tested here were selected based on prior publications (Harris et al., 2007; España et al., 2010; James et al., 2011; Mahler et al., 2013).

Locomotor control tests. A separate group of rats were given locomotor activity tests before extinction training or after reinstatement testing in a counterbalanced design. Locomotor activity was assessed as described previously (McGlinchey et al., 2016; James et al., 2018a). Briefly, rats were first acclimated to locomotor chambers (clear acrylic, $40 \times 40 \times 30 \mathrm{~cm}$ ) with Digiscan monitors (AccuScan Instruments) for $2 \mathrm{~h}$. The next day, rats received a counterbalanced microinjection of either $\mathrm{SB}(1.0 \mathrm{mM})$ or aCSF 5 min before the same locomotor test in a counterbalanced design. Total, horizontal, and vertical locomotor activities were recorded using beam beaks. Rats underwent a $1 \mathrm{~d}$ washout period between locomotor test sessions, in which they were placed in the locomotor chamber but did not receive treatment. Altogether, rats received a maximum of six microinjections.

Localization of injection sites. After the final behavioral test, rats were deeply anesthetized with ketamine/xylazine $(56.6 / 8.7 \mathrm{mg} / \mathrm{kg})$ and bilateral microinfusions of pontamine sky blue were performed $(0.3$ $\mu 1 /$ side). Brains were removed and flash-frozen in 2-methylbutane, cut on a cryostat into $40-\mu \mathrm{m}$-thick frontal sections, mounted on glass slides, Nissl-stained with neutral red, and coverslipped to localize cannula tract damage and verify injection sites. Subjects with cannulae implanted outside the cVP (AP 0.0 to $-0.8 \mathrm{~mm}$ relative to bregma) or with excessive damage along the cannula track were excluded from all analyses $(n=6)$.

Data analysis. Data are expressed as mean values \pm 1 SEM. Statistics were performed using GraphPad Prism for Mac version 7 and SPSS

$\leftarrow$

(Figure legend continued.) elasticity ( $\alpha$;decreased motivation; paired-samples $t$ tests; ${ }^{*} p=$ $0.031)$. G, SB (30 mg/kg, i.p.) also decreased remifentanil consumption at null cost $\left(Q_{0} ;\right.$ pairedsamples $t$ tests; $\left.{ }^{*} p=0.041\right)$. $\boldsymbol{H}$, After BE testing, rats $(n=9)$ underwent extinction training. Lever presses decreased significantly across the 7 extinction sessions (mixed-design ANOVA; $p=0.0002$ ). I, After extinction training, rats were tested for cued reinstatement of remifentanil-seeking. After vehicle treatment, presentation of remifentanil-associated cues resulted in a significant reinstatement of active lever pressing compared with extinction ( $r m$ ANOVA with Bonferroni comparison; ${ }^{*} p=0.002$ ). This reinstatement of responding was significantly attenuated by pretreatment with $\mathrm{SB}\left(30 \mathrm{mg} / \mathrm{kg}\right.$, i.p.; Bonferroni comparison; ${ }^{*} p=$ $0.011)$. J, SB had no effect on inactive lever presses during reinstatement testing ( $r m-A N O V A ;$ $p=0.773)$
Statistics (V19) with an $\alpha$ level of 0.05 . FR-1 self-administration and extinction data were analyzed using mixed-design ANOVAs with Bonferroni corrections as post hoc tests. Demand parameters $\left(Q_{0}\right.$ and $\left.\alpha\right)$ were expressed as percentage change relative to baseline, which was the average of the three sessions immediately before the first test. Paired-sample $t$ tests were performed to determine the effects of systemic and intra-VP SB on remifentanil demand, cue-induced reinstatement, and locomotor activity. Bonferroni corrections were applied when multiple $t$ tests were performed. Student's $t$ test was performed to determine whether $Q_{0}$ or $\alpha$ values differed from baseline after dorsal control injections. The effects of systemic and intra-VP SB were assessed using one-way repeated-measures $(\mathrm{rm})$-ANOVAs with Bonferroni corrections as post hoc tests. The effects of intra-VP SB on extinction responding were assessed using independent-samples $t$ tests. A linear regression was used to correlate individual $Q_{0}$ and $\alpha$ values. For multiple linear regression analyses, $Q_{0}$ and $\alpha$ values were set as the independent variables, with the dependent variables being active lever responses during cued reinstatement or the difference in responding between $\mathrm{SB}$ and vehicle treatments.

\section{Results}

\section{Systemic blockade of OxR1s reduced remifentanil demand} and cue-induced reinstatement of remifentanil seeking

Figure $1 A$ outlines the experimental timeline of behavioral testing. During FR-1 self-administration training, rats $(n=11)$ made more responses on the active than the inactive lever (mixeddesign ANOVA; main effect of lever type: $F_{(11,131)}=3.501, p=$ 0.0003 ) beginning on the third session (Bonferroni correction, $p=0.017)$ and lasting throughout the remaining training sessions (Fig. $1 B$ ). Remifentanil infusions also increased across training (Fig. $1 C$; rm-ANOVA; $F_{(5,65)}=11.64, p=0.0003$ ).

Once FR1 self-administration was acquired, rats $(n=10)$ were trained on a within-session BE procedure to assess demand for remifentanil. Figure $1 D$ shows a demand curve generated with this procedure for a representative rat and session. A significant inverse correlation was observed between baseline demand elasticity $(\alpha)$ and preferred intake at null cost $\left(Q_{0}\right.$; Fig. $1 E$; linear regression; $r=-0.678, p=0.031$ ), such that individuals with high $Q_{0}$ values were less sensitive to changes in price. Consistent with our previous findings, blockade of OxR1s with SB $(30 \mathrm{mg} / \mathrm{kg})$ significantly increased demand elasticity (increased $\alpha$; pairedsamples $t$ test; Fig. $\left.1 F ; t_{(9)}=2.551, p=0.031, d=0.806\right)$ and reduced remifentanil consumption at null cost $\left(Q_{0}\right.$; Fig. $1 G$; paired-samples $t$ test; $t_{(9)}=2.382, p=0.041, d=0.753$ ) compared with vehicle. Baseline $\alpha$ and Qo values did not differ between tests ( $\alpha$; paired-samples $t$ tests; first vs last injection; $t_{(9)}=$ $1.188, p=0.265, d=0.376 ; Q_{0}$; paired-samples $t$ tests; first vs last injection; $\left.t_{(9)}=1.619, p=0.140, d=0.512\right)$.

After BE testing, rats $(n=9)$ underwent extinction training and testing for cue-induced reinstatement of remifentanil seeking. Lever press responding decreased over the first seven extinction sessions (Fig. $1 H$; mixed-design ANOVA; main effect of Session $\left.F_{(1,8)}=43.01, p=0.0002\right)$. After reaching extinction criterion, rats were given an injection of vehicle or SB $(30 \mathrm{mg} / \mathrm{kg}$, i.p.) before reinstatement tests. An rm-ANOVA and post hoc analysis revealed that the presentation of remifentanil-associated cues induced a significant reinstatement of drug seeking as measured by increased responding on the active lever (rm-ANOVA, $F_{(2,16)}=9.182, p=0.002, \eta^{2}=0.534$; extinction vs vehicle, Bonferroni correction, $p=0.002 ; d=1.21$; Fig. $1 I$ ). SB significantly reduced active lever presses compared with vehicle (SB vs vehicle; Bonferroni correction, $p=0.011 ; d=1.560)$. Changes in inactive lever responding were not observed (Fig. 1J; rmANOVA; $\left.F_{(2,16)}=0.260, p=0.773, \eta^{2}=0.032\right)$. 


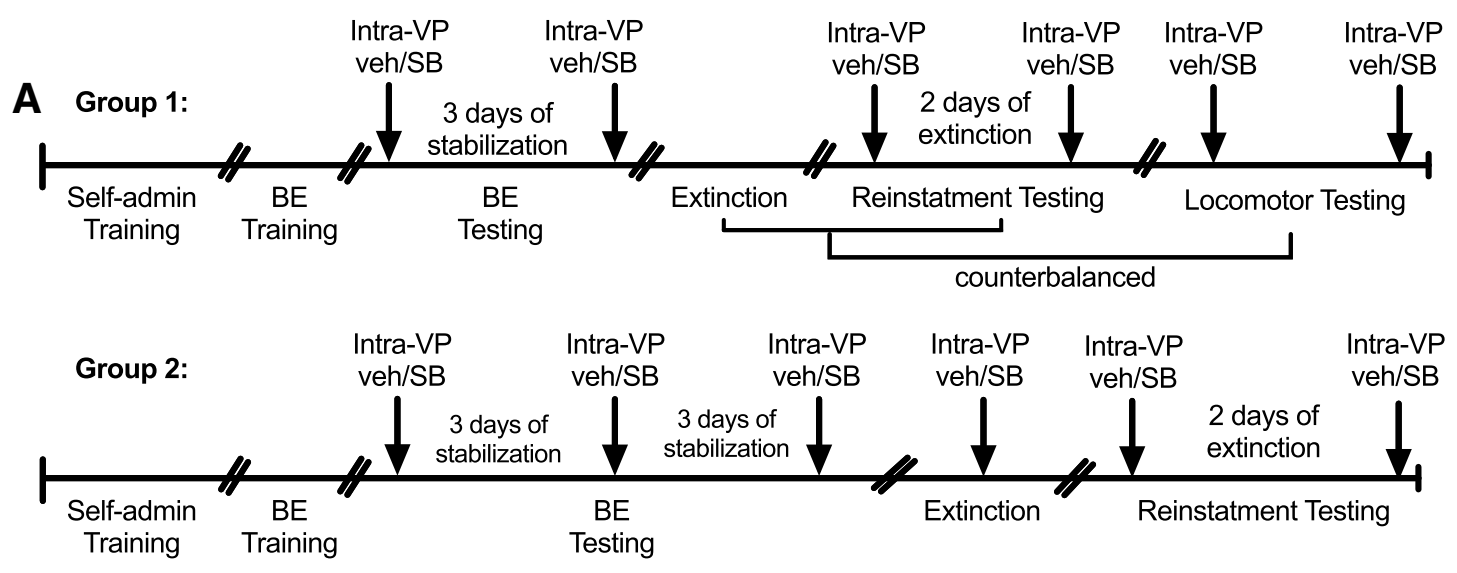

B Bregma Level $-0.8 \mathrm{~mm}$

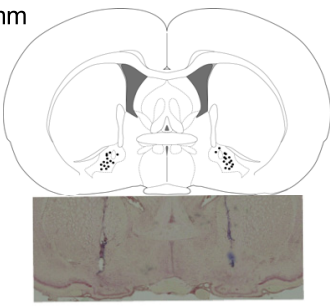

E

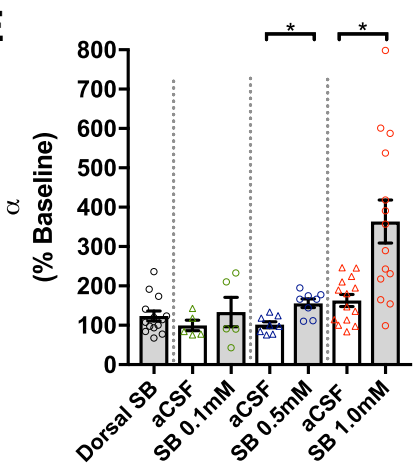

H

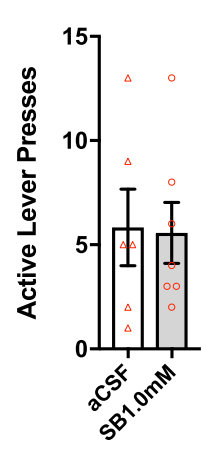

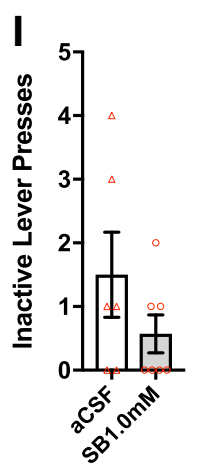

C

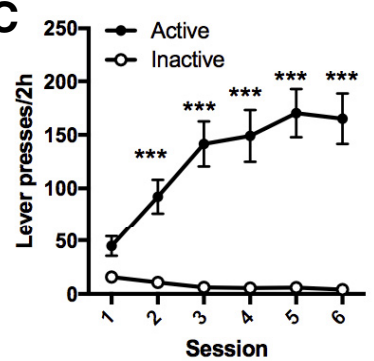

F

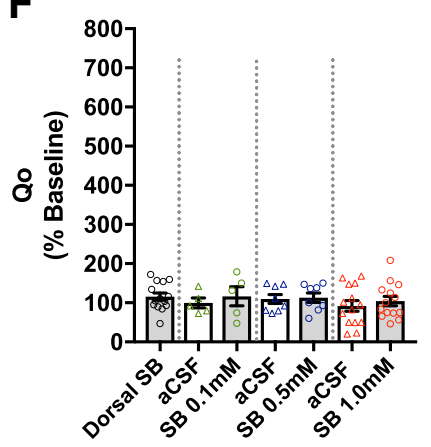

J

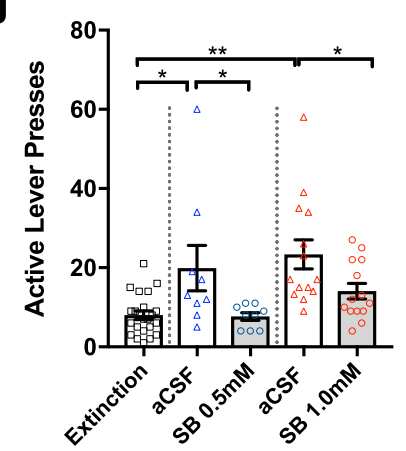

D

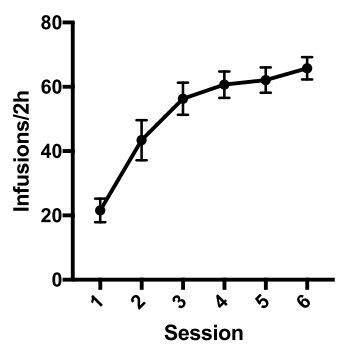

G

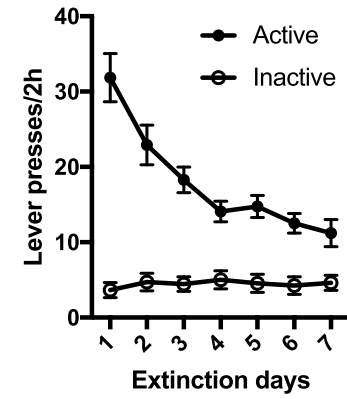

K

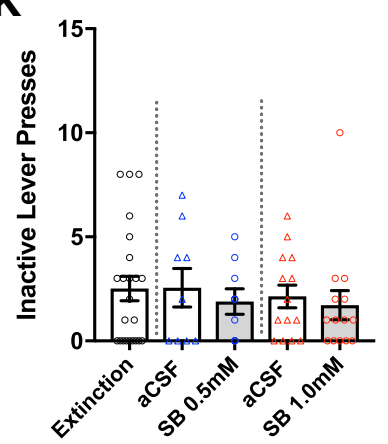

Figure 2. Intra-VP microinjections of SB decreased motivation and attenuated reinstatement of remifentanil seeking. $\boldsymbol{A}$, Timeline for behavioral procedure. $\boldsymbol{B}$, Schematic depicting the location of injector tips for intra-VP microinfusions of SB (top) and a representative photomicrograph of cannula injection sites (neutral red Nissl stain, frontal section, midline at center; bottom). Top figure adapted from Paxinos and Watson (1998). The same animals received intra-VP SB 1 mm also received control injections $1.8 \mathrm{~mm}$ dorsal to the injections sites depicted here. $\boldsymbol{C}$, Rats were trained to self-administer remifentanil on an FR1 schedule. Data reflect the final $6 \mathrm{~d}$ of self-administration training. Rats $(n=25)$ readily learned to discriminate between the active and inactive levers and made significantly more active vs inactive lever presses across the final 5 self-administration sessions (mixed-design ANOVA with Bonferroni comparison; ${ }^{* * *} p<0.0001$ ). $\boldsymbol{D}$, The number of remifentanil infusions earned increased significantly across the FR1 training period (rm-ANOVA; $p<0.0001$ ). $E$, After self-administration training, rats were trained and tested on a within-session BE procedure. Rats received intra-VP microinjections for $S B$ immediately before testing on the BE paradigm SB dose-dependently increased demand elasticity $(\alpha)$; a significant increase in $\alpha$ values occurred after $0.5 \mathrm{~mm}\left(n=8 ;\right.$ paired-samples $t$ test; $\left.{ }^{*} p=0.0002\right)$ and $1.0 \mathrm{~mm} \mathrm{SB}(n=14$; paired-samples $t$ test; $\left.{ }^{*} p=0.003\right)$. No difference was observed after $0.1 \mathrm{~mm} \mathrm{SB}(n=5)$. There was also no effect of SB $(1.0 \mathrm{~mm})$ when infused $1.8 \mathrm{~mm}$ dorsal to VP. $\boldsymbol{F}$, Intra-VPSB had no effect on remifentanil consumption at null $\operatorname{cost}\left(Q_{0}\right)$.G,After BEtesting, rats $(n=25)$ underwent extinction training. Again, responding decreased significantly across the 7 extinction sessions (mixed-design ANOVA; $\left.p<0.0001\right) . \boldsymbol{H}$, When tested in late extinction, intra-VPSB $(n=7 ; 1.0 \mathrm{~mm}$ ) had no significant effecton active lever pressing compared with aCSF controls $(n=6$; independent-samplesttest; $p=0.912) . I$, Similarly, intra-VPSB had no effecton inactivelever pressing in late extinction ( $n=6$; independent-samples $t$ test; $p=0.209$ ).J, After extinction training, rats were tested for cued reinstatement of remifentanil seeking. After intra-VP microinjections (Figurelegend continues.) 
A

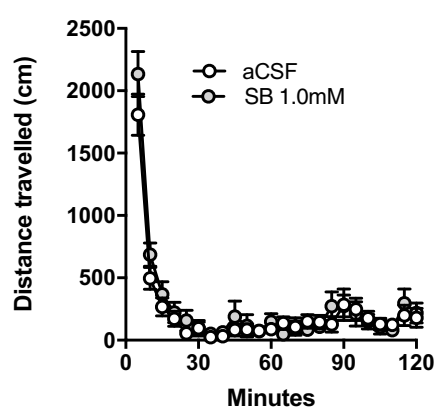

B

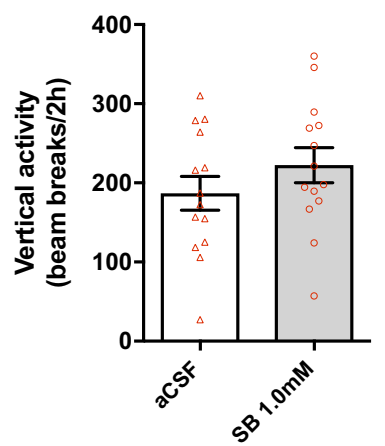

C

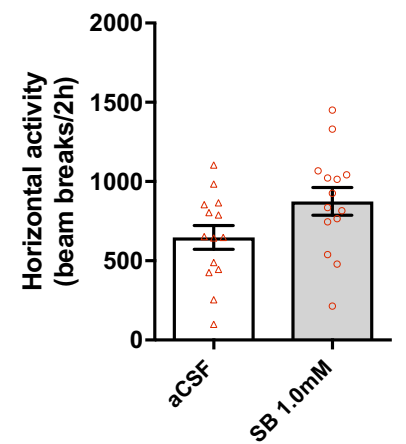

Figure 3. Intra-VP SB had no effect on general locomotor activity. The effect of intra-VP SB (1.0 mm) on general locomotor activity was assessed ( $n=14)$ to determine whether intra-VP SB impaired locomotor activity in rats that had previously undergone remifentanil demand testing. Intra-VP SB had no effect on $\boldsymbol{A}$ ) total distance traveled, $\boldsymbol{B}$ ) horizontal or $\boldsymbol{C}$ ) vertical activity (paired-samples $t$ tests; $p=0.985, p=0.343, p=0.0754$ ).

\section{Antagonism of OxR1s in VP selectively reduced motivation for remifentanil and attenuated cue-induced reinstatement of remifentanil seeking}

We next sought to determine the role of VP OxR1 signaling in demand for remifentanil. Figure $2 A$ outlines the experimental timeline of behavioral testing, and Figure $2 B$ illustrates VP cannulae placements. Similar to the prior group, rats $(n=25)$ readily acquired remifentanil FR1 self-administration, making more responses on the active than the inactive lever across the final 5 sessions (Fig. 2C; mixed-design ANOVA; main effect of lever type $\left(F_{(5,24)}=53.24, p<0.0001\right.$, Bonferroni post hoc comparisons $p<$ $0.0001)$. Similarly, remifentanil infusions increased across training (Fig. 2D; rm-ANOVA; $F_{(5,120)}=29.41, p<0.0001$ ).

Next, rats $(n=22)$ were trained and tested on the withinsession $\mathrm{BE}$ procedure for remifentanil. Again, a significant inverse correlation was observed between baseline demand elasticity $(\alpha)$ and remifentanil consumption at null cost $\left(Q_{0}\right.$; linear regression; $\mathrm{r}-0.8405, p=0.0002$; data not shown). Dorsal control microinfusion of SB ( $1.0 \mathrm{mM}, n=14)$ had no effect on demand elasticity (Student's $t$ test; $t_{(13)}=1.663, p=0.1202, d=0.497$ ) or consumption at null cost (Student's $t$ test, $t_{(13)}=1.663, p=0.119$; $d=0.447)$.

Microinfusion of SB into VP dose-dependently increased demand elasticity ( $\alpha$; Fig. $2 E)$. Microinfusion of $0.5 \mathrm{mM}(n=8)$ or $1.0 \mathrm{mM} \mathrm{SB}(n=14)$ into cVP significantly increased demand elasticity relative to their respective aCSF controls (pairedsamples $t$ tests; SB $0.5 \mathrm{~mm}$ vs aCSF $\mathrm{t}_{7}=7.059, p=0.0002, d=$ 2.50; SB $1.0 \mathrm{~mm}$ vs aCSF $\left.t_{(13)}=3.643, p=0.003, d=0.974\right)$. Microinfusion of $0.1 \mathrm{mM} \mathrm{SB}(n=5)$ had no effect on demand elasticity (paired-samples $t$ test, $\mathrm{t}_{4}=1.269, p=0.273, d=0.568$ ). Notably, in contrast to systemic injections of SB, intra-VP microinfusions of SB had no effect on $Q_{0}$ (Fig. $2 F$; paired-samples $t$ tests; SB $0.1 \mathrm{mM}$ vs aCSF t $\mathrm{t}_{4}=0.656, p=0.548,0.293$; SB $0.5 \mathrm{~mm}$ vs aCSF $t_{7}=0.190, p=0.855, d=0.0670 ;$ SB $1.0 \mathrm{~mm}$ vs aCSF $\left.t_{(13)}=0.627, p=0.542, d=0.167\right)$. Baseline $\alpha$ and Qo values did not differ between tests ( $\alpha$; paired-samples $t$ tests; first vs last microinfusion; $t_{(21)}=1.506, p=0.147, d=0.321$; Qo; paired-

$\leftarrow$

(Figure legend continued.) with vehicle, presentation of remifentanil-associated cues reinstated active lever pressing (rm-ANOVAs with Bonferroni comparisons; ${ }^{*} p<0.05 ;{ }^{* *} p=0.0007$ ). This was attenuated by intra-VP microinjections of $S B$ at both $0.5 \mathrm{~mm}(n=9)$ and $1.0 \mathrm{~mm}$ doses $\left(n=14\right.$, Bonferroni comparisons; $\left.{ }^{*} p<0.05\right)$. $\boldsymbol{K}, \mathrm{SB}$ had no effect on inactive lever presses during cued reinstatement testing (rm-ANOVAs). samples $t$ tests; first vs last microinfusion; $t_{(21)}=1.086, p=0.289$, $d=0.232$ ).

We next sought to determine the role of VP OxR1 signaling in cue-induced reinstatement behavior. Rats were trained on extinction by eliminating drug infusions and cues; responding decreased over the first 7 extinction sessions (Fig. 2G; mixed-design ANOVA; main effect of Session $\left.F_{(6,144)}=11.84, p<0.0001\right)$. Microinfusion of SB ( $1.0 \mathrm{mM} ; n=7)$ in VP had no effect on either active (Fig. $2 H$; independent-samples $t$ tests; $t_{(11)}=0.113, p=$ $0.912, d=0.0625$ ) or inactive lever responding (Fig. 2I; independent-samples $t$ tests; $t_{(11)}=1.334, p=0.209, d=0.721$ ) in late extinction compared with aCSF controls $(n=6)$. In contrast, SB (0.5 mM and $1.0 \mathrm{~mm})$ significantly attenuated cueinduced remifentanil seeking (Fig. 2J; SB $0.5 \mathrm{mM}, n=9$, rmANOVA, $F_{(2,16)}=5.65, p=0.014, \eta^{2}=0.414$; SB $1.0 \mathrm{mM}, n=14$, rm-ANOVA, $\left.F_{(2,26)}=8.82, p=0.001, \eta^{2}=0.404\right)$. Post hoc analyses revealed that the presentation of remifentanil-associated cues induced a significant reinstatement of drug seeking in both vehicle groups (SB $0.5 \mathrm{~mm}$ : extinction vs aCSF, $p=0.011, d=$ 0.852 ; SB 1.0 mM: extinction vs aCSF, $p=0.0007, d=0.822$; Bonferroni corrections applied). Compared with aCSF, SB (0.5 $\mathrm{mM}$ and $1.0 \mathrm{mM}$ ) significantly reduced active lever presses (SB 0.5 mu vs aCSF, $p=0.0392, d=0.714$; SB $1.0 \mathrm{~mm}$ vs aCSF, $p=0.016$, $d=0.910$; Bonferroni corrections applied). SB (0.5 mM and 1.0 $\mathrm{mM}$ ) had no effect on inactive lever responding (Fig. $2 \mathrm{~K}$; SB 0.5 $\mathrm{mm} F_{(2,16)}=0.448, p=0.647, d=0.216$; SB $1.0 \mathrm{mM} F_{(2,26)}=$ $0.283, p=0.756, d=0.141)$.

To examine whether the effects of intra-VP SB on demand elasticity and cued reinstatement were due to motor impairments, we tested SB (1.0 mM) microinfusions on locomotor activity $(n=14)$. SB $(1.0 \mathrm{~mm})$ had no effect on total distance traveled (Fig. $\left.3 A ; t_{(13)}=0.985 ; p=0.343 ; d=0.250\right)$, horizontal activity (Fig. $\left.3 B ; t_{(13)}=1.032 ; p=0.0754 ; d=0.742\right)$ or vertical activity (Fig. $\left.3 C ; t_{(13)}=1.436 ; p=0.175 ; d=0.436\right)$ during a $2 \mathrm{~h}$ general locomotor test (after acclimation, as above). Notably, locomotor activity and reinstatement behavior was similar across animals, regardless of whether animals underwent extinction/ reinstatement or locomotor testing first (reinstatement [active lever responses]: $p=0.6724$; total distance traveled: $p=0.6393$, data not shown), indicating that similar to previous studies, there were no large nonspecific behavioral effects associated with up to 6 intraparenchymal microinjections (Mahler et al., 2013; McGlinchey et al., 2016; James et al., 2018a). Together, these results indicate 
A

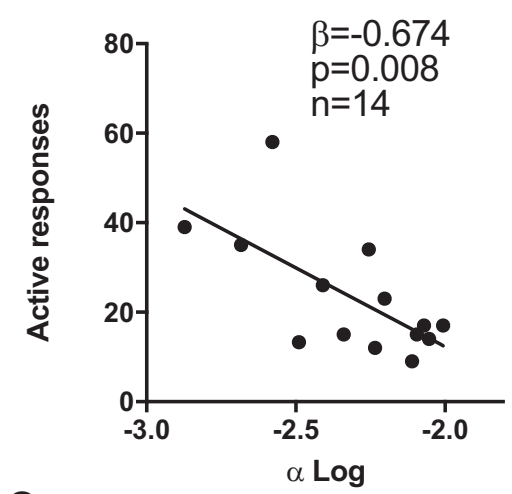

C

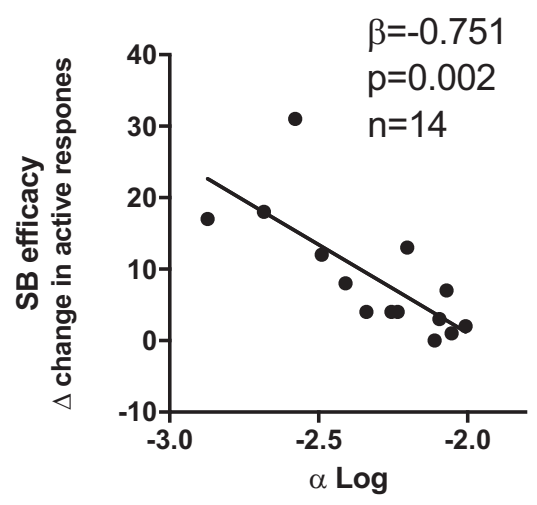

B

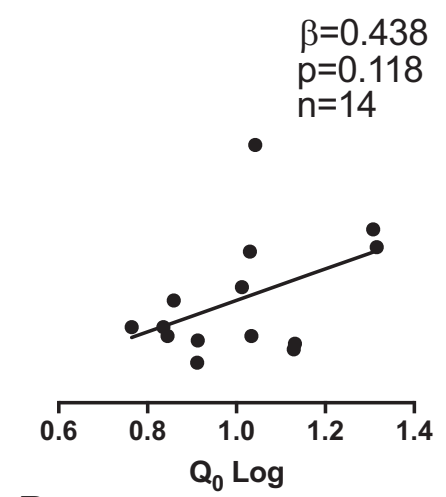

D

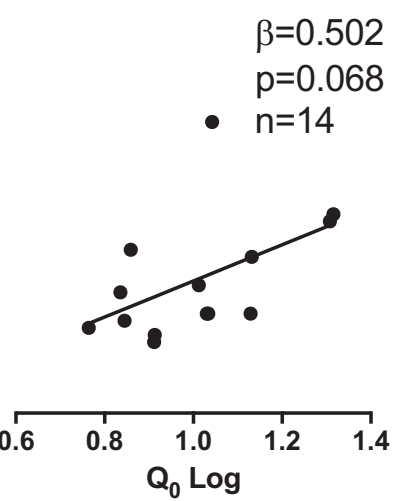

Figure 4. Baseline demand elasticity predicted reinstatement propensity and efficacy of intra-VP SB microinfusions on demand. $\boldsymbol{A}$, Baseline demand elasticity $(\alpha)$ was significantly negatively correlated with the magnitude of cued reinstatement after intra-VP vehicle, such that animals with higher motivation (lower $\alpha$ ) exhibited higher reinstatement. $\boldsymbol{B}$, Baseline remifentanil consumption under free access conditions $\left(Q_{0}\right)$ was not significantly correlated with cued reinstatement behavior. $C$, Baseline demand elasticity $(\alpha)$ correlated with the reduction of cue-induced reinstatement after SB microinjection into cVP. That is, intra-VP microinjections of SB were more effective at reducing cued reinstatement in animals with higher baseline motivation (lower $\alpha$ ) for remifentanil. D, Baseline remifentanil consumption under null cost conditions was also correlated with the magnitude of the reduction of cue-induced reinstatement with SB microinjection into VP, but this failed to reach statistical significance $\left(Q_{0}\right) . n=14$ for all correlations.

that the effects of SB on demand elasticity and reinstatement were not due to motor impairment.

\section{Baseline demand for remifentanil predicts cue-induced reinstatement and SB efficacy}

We previously reported that baseline demand for cocaine and fentanyl predicted other addiction behaviors including cueinduced reinstatement (Bentzley et al., 2014; James et al., 2019; Fragale et al., 2019). Thus, we sought to determine whether baseline demand for remifentanil also predicted reinstatement of remifentanil seeking (as measured by active lever responding). Multiple linear regression analyses revealed that baseline $\alpha$ was negatively correlated with reinstatement (Fig. $4 A ; \beta=-0.674$, $p=0.008$ ) such that reinstatement behavior was greatest in highly motivated rats after aCSF microinfusion. No relationship was observed between baseline $Q_{0}$ and reinstatement (Fig. $4 B$; $\beta=0.438, p=0.118$ ).

Baseline demand has also been shown to predict the antimotivational effects of systemic SB treatment (James et al., 2019; Fragale et al., 2019). Consistent with such previous findings, baseline $\alpha$ was negatively correlated with intra-VP SB efficacy (1.0 mM; Fig. $4 C ; \beta=-0.751, p=0.002$ ), such that intra-VP SB was most effective at attenuating reinstatement behavior in highly motivated rats. A nonsignificant trend was observed for $Q_{0}(1.0 \mathrm{~mm}$; Fig. $4 D ; \beta=-0.502, p=0.068)$.

\section{Discussion}

Here, we confirm previous findings showing that systemic blockade of OxR1s reduces motivation for remifentanil (increases $\alpha$, demand elasticity), decreases remifentanil consumption at null cost $\left(Q_{0}\right)$, and attenuates cue-induced reinstatement of remifentanil seeking (PorterStransky et al., 2017). We also extend these findings to show that OxR1 signaling in the VP selectively regulates motivation $(\alpha)$ for remifentanil and reinstatement of remifentanil seeking but not low effort consumption $\left(Q_{0}\right)$ or extinction responding. Finally, we show that baseline $\alpha$ values predict reinstatement behavior and the efficacy of intra-VP SB in reducing cueinduced drug seeking. Together, these findings indicate a specific role for VP OxR1 signaling in motivated responding for remifentanil. Moreover, these results highlight the utility of $\mathrm{BE}$ in predicting relapse propensity and in identifying individuals most likely to benefit from orexin-based pharmacotherapies.

A clear role has been established for OxR1 signaling in drug seeking behavior (Harris et al., 2005; Mahler et al., 2014; James et al., 2017). Signaling at the OxR1 preferentially mediates high-effort drug seeking/taking or when drug motivation is augmented by external stimuli (Harris et al., 2005; Smith and Aston-Jones, 2012; Bentzley and Aston-Jones, 2015; PorterStransky et al., 2017; Fragale et al., 2019). We previously found that this role extends to opioids, as systemic SB reduced motivated responding for heroin (Smith and Aston-Jones, 2012), fentanyl (Fragale et al., 2019) and remifentanil (Porter-Stransky et al., 2017). However, whereas OxR1 signaling appears to play a minor role in low-effort consumption of cocaine (Bentzley and Aston-Jones, 2015; James et al., 2018b), it may play a greater role in regulating low-effort responding for opioids. We previously found that systemic SB reduced FR-1 responding for heroin (Smith and Aston-Jones, 2012) and consumption of remifentanil at null cost $\left(Q_{0}\right)$ (Porter-Stransky et al., 2017). Here, we confirm a role for OxR1 signaling in both high- and low-effort consumption of remifentanil, finding that systemic SB both increased $\alpha$ (decreased motivation) and decreased $Q_{0}$ (low-effort consumption) values. However, the role of OxR1 signaling in low-effort responding for opioids is complex. Using an identical withinsession BE procedure, we recently reported that systemic SB decreased motivation for the opioid fentanyl (increased $\alpha$ ) without affecting $Q_{0}$ (Fragale et al., 2019). This result may reflect differences in the pharmacokinetics of remifentanil vs fentanyl. Moreover, as in our previous paper (Porter-Stransky et al., 2017), we observed an increase in $Q_{0}$ values relative to baseline after vehicle treatment, which was significantly reduced by SB. Together, these data point to a need for addi- 
tional studies to further specify the roles of OxR1 signaling in opioid demand.

We investigated VP as a potential site of action for SB in mediating remifentanil seeking behaviors, as this region has been implicated in both motivational and hedonic processing. In addition, VP receives moderate orexin input and expresses a high density of OxR1s (Marcus et al., 2001; Baldo et al., 2003), indicating that this region may be a site for orexin modulation of reward behavior. Intra-VP microinfusions of SB increased demand elasticity ( $\alpha$; decreased motivation) but had no effect on remifentanil intake at null cost $\left(Q_{0}\right)$. These SB effects were localized to $\mathrm{VP}$, as we observed no effect of SB microinfusions dorsal to VP (along the cannula tract, a likely path of diffusion). VP is a key component of brain circuitry regulating effort-related choice behavior, as VP inactivation reduces willingness to work in an instrumental task to obtain sucrose reward (Farrar et al., 2008). Interestingly however, there is evidence that orexin signaling in VP also mediates the hedonic properties of reward. Microinjections of orexin-A into VP enhanced the hedonic responses ('liking') for sucrose, as assessed by an affective taste reactivity test (Ho and Berridge, 2013). We previously argued that $Q_{0}$ might reflect an animal's hedonic set point for drug (Bentzley et al., 2014), but this hypothesis is difficult to test directly. Thus, we are unable to draw definitive conclusions from our data regarding a role for OxR1 signaling in VP in hedonic properties of remifentanil. It is unlikely that the lack of effect of intra-VP SB on $Q_{0}$ resulted from using a subthreshold dose of $\mathrm{SB}$, as this dose produced robust behavioral effects in other paradigms (Harris et al., 2007; Mahler et al., 2013) and a lower dose was effective in attenuating motivation for remifentanil. It is possible that the previously reported effects of orexin-A infusions into VP to increase 'liking' for sucrose may be mediated by actions at Ox2Rs, as orexin-A has similar affinity for OxR1 and Ox2R (Sakurai et al., 1998b), and Ox2Rs are expressed in VP (Marcus et al., 2001). It is also possible that the orexin system plays distinct roles in mediating the hedonic aspects of natural versus drug reward. Clearly, further studies are required to test these and other possibilities.

Systemic SB is highly effective at reducing cue-induced reinstatement of extinguished drug seeking (Smith et al., 2009; Smith and Aston-Jones, 2012; Plaza-Zabala et al., 2013; Moorman et al., 2017; Fragale et al., 2019). Such findings led us to hypothesize that the orexin system provides motivational activation by reward-associated stimuli (Mahler et al., 2014; James et al., 2017). Consistent with this view, we found that both systemic and intra-VP SB reduced cue-induced reinstatement of extinguished remifentanil seeking. However, it is important to recognize that VP is part of a broader reward network that underlies reinstatement behavior (McFarland and Kalivas, 2001; Prasad and McNally, 2016). Thus, it is possible that OxR1 signaling at other sites may contribute to this behavior (James and Dayas, 2013; Qi et al., 2013; Matzeu et al., 2018). It will therefore be important that future studies seek to identify the relative contribution of VP OxR1 signaling versus other key reward regions in reinstatement of opioid seeking.

The orexin system is important for motivated responding for natural rewards (Cason and Aston-Jones, 2013a,b) and thus it is possible that the effect of intra-VP infusions on motivation for remifentanil would also extend to motivated food seeking. Importantly however, evidence indicates that doses of SB that are sufficient to block drug seeking (such as those used here) have no effect on regular chow intake in ad libitum-fed animals (Borgland et al., 2009; Choi et al., 2010; Alcaraz-Iborra et al., 2014), indicating that any potential orexin-based therapy designed to reduce craving and motivation for opioid reward may not interfere with homeostatic feeding.

We previously reported that baseline demand elasticity is a strong predictor of several addiction-relevant endophenotypes (Bentzley et al., 2014; James et al., 2019; Fragale et al., 2019). Moreover, we showed that SB is most effective at reducing motivation for cocaine, fentanyl, and alcohol in highly motivated animals (Lopez et al., 2016; Moorman et al., 2017; James et al., 2018b, 2019; Fragale et al., 2019) and that motivation for cocaine is higher in rats with more orexin neurons (James et al., 2018b; Pantazis et al., 2019). Here, we found that animals with high baseline motivation for remifentanil also have strong reinstatement behavior. We also show that highly motivated animals exhibited the largest reduction in reinstatement behavior after intra-VP SB, indicating that demand elasticity might also be useful for identifying those individuals most likely to benefit from the therapeutic effects of OxR1 antagonist. Given that the BE paradigm can be readily applied in clinical populations (MacKillop et al., 2019), our findings point to the potential utility of this approach for identifying those individuals most likely to relapse after abstinence, and to benefit from pharmacotherapies that target orexin signaling.

It is possible that blocking OxR1 signaling in our experiments affected general motor behavior. The orexin system plays a strong role in arousal (Tsujino and Sakurai, 2013; Li et al., 2014, 2017) and VP is a known modulator of locomotor activation (Swerdlow et al., 1984; Williams and Herberg, 1987). However, we previously found that systemic SB only modestly reduced general locomotor activity in rats with a history of remifentanil selfadministration, and that the magnitude of this reduction was not related to SB's effects on $\alpha$ or $Q_{0}$ (Porter-Stransky et al., 2017). Here, we show that intra-VP SB had no effect on general locomotor activity. Moreover, intra-VP SB failed to alter extinction responding. In support of our findings, other studies have also failed to observe nonspecific motor deficits after local injections of SB into other reward regions (Borgland et al., 2009; James et al., 2011; Mahler et al., 2013). Thus, the effects of intra-VP SB on demand elasticity and reinstatement are not likely due to motor impairment.

In conclusion, our results add to a growing body of findings implicating the orexin system as a target for treating opioid abuse, and provide new insights into the corresponding neural substrates. We also show that $\mathrm{BE}$ provides a predictive behavioral marker of remifentanil seeking behaviors and the anti-drug seeking efficacy of SB, and thus could be applied clinically to determine opioid addiction liability and optimize pharmacological treatment strategies.

\section{References}

Alcaraz-Iborra M, Carvajal F, Lerma-Cabrera JM, Valor LM, Cubero I (2014) Binge-like consumption of caloric and non-caloric palatable substances in ad libitum-fed C57BL/6J mice: pharmacological and molecular evidence of orexin involvement. Behav Brain Res 272:93-99.

Baimel C, Bartlett SE, Chiou LC, Lawrence AJ, Muschamp JW, Patkar O, Tung LW, Borgland SL (2015) Orexin/hypocretin role in reward: implications for opioid and other addictions. Br J Pharmacol 172:334-348.

Baldo BA, Daniel RA, Berridge CW, Kelley AE (2003) Overlapping distributions of orexin/hypocretin- and dopamine-beta-hydroxylase immunoreactive fibers in rat brain regions mediating arousal, motivation, and stress. J Comp Neurol 464:220-237.

Baylon GJ, Kaplan HL, Somer G, Busto UE, Sellers EM (2000) Comparative abuse liability of intravenously administered remifentanil and fentanyl. J Clin Psychopharmacol 20:597-606.

Bentzley BS, Aston-Jones G (2015) Orexin-1 receptor signaling increases motivation for cocaine-associated cues. Eur J Neurosci 41:1149-1156. 
Bentzley BS, Fender KM, Aston-Jones G (2013) The behavioral economics of drug self-administration: a review and new analytical approach for within-session procedures. Psychopharmacology 226:113-125.

Bentzley BS, Jhou TC, Aston-Jones G (2014) Economic demand predicts addiction-like behavior and therapeutic efficacy of oxytocin in the rat. Proc Natl Acad Sci U S A 111:11822-11827.

Borgland SL, Chang SJ, Bowers MS, Thompson JL, Vittoz N, Floresco SB, Chou J, Chen BT, Bonci A (2009) Orexin A/hypocretin-1 selectively promotes motivation for positive reinforcers. J Neurosci 29:11215-11225.

Cason AM, Aston-Jones G (2013a) Attenuation of saccharin-seeking in rats by orexin/hypocretin receptor 1 antagonist. Psychopharmacology 228:499-507.

Cason AM, Aston-Jones G (2013b) Role of orexin/hypocretin in conditioned sucrose-seeking in rats. Psychopharmacology 226:155-165.

Choi DL, Davis JF, Fitzgerald ME, Benoit SC (2010) The role of orexin-A in food motivation, reward-based feeding behavior and food-induced neuronal activation in rats. Neuroscience 167:11-20.

Compton WM, Volkow ND (2006) Major increases in opioid analgesic abuse in the United States: concerns and strategies. Drug Alcohol Depend 81:103-107.

Dallimore JE, Mickiewicz AL, Napier TC (2006) Intra-ventral pallidal glutamate antagonists block expression of morphine-induced place preference. Behav Neurosci 120:1103-1114.

de Lecea L, Kilduff TS, Peyron C, Gao X, Foye PE, Danielson PE, Fukuhara C, Battenberg EL, Gautvik VT, Bartlett FS 2nd, Frankel WN, van den Pol AN, Bloom FE, Gautvik KM, Sutcliffe JG (1998) The hypocretins: hypothalamus-specific peptides with neuroexcitatory activity. Proc Natl Acad Sci U S A 95, 322-327.

Dobbs GC, Fogger SA (2018) Opiate dependence or addiction?: a review of the centers for disease control and prevention guidelines for management of chronic pain. J Addict Nurs 29:57-61.

España RA, Oleson EB, Locke JL, Brookshire BR, Roberts DC, Jones SR (2010) The hypocretin-orexin system regulates cocaine self-administration via actions on the mesolimbic dopamine system. Eur J Neurosci 31:336-348.

Farrar AM, Font L, Pereira M, Mingote S, Bunce JG, Chrobak JJ, Salamone JD (2008) Forebrain circuitry involved in effort-related choice: injections of the GABAA agonist muscimol into ventral pallidum alter response allocation in food-seeking behavior. Neuroscience 152:321-330.

Fragale JE, Pantazis CB, James MH, Aston-Jones G (2019) The role of orexin-1 receptor signaling in demand for the opioid fentanyl. Neuropsychopharmacology 44:1690-1697.

Glass PS, Gan TJ, Howell S (1999) A review of the pharmacokinetics and pharmacodynamics of remifentanil. Anesth Analg 89:S7-S14.

Harris GC, Wimmer M, Aston-Jones G (2005) A role for lateral hypothalamic orexin neurons in reward seeking. Nature 437:556-559.

Harris GC, Wimmer M, Randall-Thompson JF, Aston-Jones G (2007) Lateral hypothalamic orexin neurons are critically involved in learning to associate an environment with morphine reward. Behav Brain Res 183: $43-51$.

Ho CY, Berridge KC (2013) An orexin hotspot in ventral pallidum amplifies hedonic 'liking' for sweetness. Neuropsychopharmacology 38:1655-1664.

Hubner CB, Koob GF (1990) The ventral pallidum plays a role in mediating cocaine and heroin self-administration in the rat. Brain Res 508:20-29.

Hursh SR, Silberberg A (2008) Economic demand and essential value. Psychol Rev 115:186-198.

James MH, Dayas CV (2013) What about me? The PVT: a role for the paraventricular thalamus (PVT) in drug-seeking behavior. Front Behav Neurosci 7:18.

James MH, Charnley JL, Levi EM, Jones E, Yeoh JW, Smith DW, Dayas CV (2011) Orexin-1 receptor signalling within the ventral tegmental area, but not the paraventricular thalamus, is critical to regulating cue-induced reinstatement of cocaine-seeking. Int J Neuropsychopharmacol 14:684-690.

James MH, Mahler SV, Moorman DE, Aston-Jones G (2017) A decade of orexin/hypocretin and addiction: where are we now? Curr Top Behav Neurosci 33:247-281.

James MH, McGlinchey EM, Vattikonda A, Mahler SV, Aston-Jones G (2018a) Cued reinstatement of cocaine but not sucrose seeking is dependent on dopamine signaling in prelimbic cortex and is associated with recruitment of prelimbic neurons that project to contralateral nucleus accumbens core. Int J Neuropsychopharmacol 21:89-94.

James MH, Stopper CM, Zimmer BA, Koll NE, Bowrey HE, Aston-Jones G (2018b) Increased Number and Activity of a Lateral Subpopulation of
Hypothalamic Orexin/Hypocretin Neurons Underlies the Expression of an Addicted State in Rats. Biol Psychiatry 85:925-935.

James MH, Bowrey HE, Stopper CM, Aston-Jones G (2019) Demand elasticity predicts addiction endophenotypes and the therapeutic efficacy of an orexin/hypocretin-1 receptor antagonist in rats. Eur J Neurosci 50:2602-2612.

Levine AI, Bryson EO (2010) Intranasal self-administration of remifentanil as the foray into opioid abuse by an anesthesia resident. Anesth Analg 110:524-525.

Lewis L, Carpenter CR, Schwarz ES, Jotte RS, Waller C, Winograd R, Williams R, Stenger S, Rehder H, Governick S, Giuffra L (2017) The opioid crisis in missouri: a call to action for physicians, legislators, and society. Mo Med 114:440-446.

Li J, Hu Z, de Lecea L (2014) The hypocretins/orexins: integrators of multiple physiological functions. Br J Pharmacol 171:332-350.

Li SB, Giardino WJ, de Lecea L (2017) Hypocretins and arousal. Curr Top Behav Neurosci 33:93-104.

Lopez MF, Moorman DE, Aston-Jones G, Becker HC (2016) The highly selective orexin/hypocretin 1 receptor antagonist GSK1059865 potently reduces ethanol drinking in ethanol dependent mice. Brain Res 1636:74-80.

MacKillop J, Goldenson NI, Kirkpatrick MG, Leventhal AM (2019) Validation of a behavioral economic purchase task for assessing drug abuse liability. Addict Biol 24:303-314.

Mahler SV, Smith RJ, Aston-Jones G (2013) Interactions between VTA orexin and glutamate in cue-induced reinstatement of cocaine seeking in rats. Psychopharmacology 226:687-698.

Mahler SV, Moorman DE, Smith RJ, James MH, Aston-Jones G (2014) Motivational activation: a unifying hypothesis of orexin/hypocretin function. Nat Neurosci 17:1298-1303.

Marcus JN, Aschkenasi CJ, Lee CE, Chemelli RM, Saper CB, Yanagisawa M, Elmquist JK (2001) Differential expression of orexin receptors 1 and 2 in the rat brain. J Comp Neurol 435:6-25.

Matzeu A, Kallupi M, George O, Schweitzer P, Martin-Fardon R (2018) Dynorphin counteracts orexin in the paraventricular nucleus of the thalamus: cellular and behavioral evidence. Neuropsychopharmacology 43: $1010-1020$.

McFarland K, Kalivas PW (2001) The circuitry mediating cocaine-induced reinstatement of drug-seeking behavior. J Neurosci 21:8655-8663.

McGlinchey EM, James MH, Mahler SV, Pantazis C, Aston-Jones G (2016) Prelimbic to accumbens core pathway is recruited in a dopaminedependent manner to drive cued reinstatement of cocaine seeking. J Neurosci 36:8700-8711.

Moorman DE, James MH, Kilroy EA, Aston-Jones G (2017) Orexin/ hypocretin-1 receptor antagonism reduces ethanol self-administration and reinstatement selectively in highly-motivated rats. Brain Res 1654:34-42.

Narita M, Nagumo Y, Hashimoto S, Narita M, Khotib J, Miyatake M, Sakurai T, Yanagisawa M, Nakamachi T, Shioda S, Suzuki T (2006) Direct involvement of orexinergic systems in the activation of the mesolimbic dopamine pathway and related behaviors induced by morphine. J Neurosci 26:398-405.

Panlilio LV, Schindler CW (2000) Self-administration of remifentanil, an ultra-short acting opioid, under continuous and progressive-ratio schedules of reinforcement in rats. Psychopharmacology 150:61-66.

Pantazis CB, James MH, Bentzley BS, Aston-Jones G (2019) The number of lateral hypothalamus orexin/hypocretin neurons contributes to individual differences in cocaine demand. Addict Biol. Advance online publication. Retrieved July 11, 2019. doi: 10.1111/adb.12795.

Paxinos G, Watson C (1998) A stereotaxic atlas of the rat brain. New York: Academic.

Peyron C, Tighe DK, van den Pol AN, de Lecea L, Heller HC, Sutcliffe JG, Kilduff TS (1998) Neurons containing hypocretin (orexin) project to multiple neuronal systems. J Neurosci 18:9996-10015.

Plaza-Zabala A, Flores Á, Martín-García E, Saravia R, Maldonado R, Berrendero F (2013) A role for hypocretin/orexin receptor-1 in cue-induced reinstatement of nicotine-seeking behavior. Neuropsychopharmacology 38:1724-1736.

Porter-Stransky KA, Bentzley BS, Aston-Jones G (2017) Individual differences in orexin-I receptor modulation of motivation for the opioid remifentanil. Addict Biol 22:303-317.

Prasad AA, McNally GP (2016) Ventral pallidum output pathways in contextinduced reinstatement of alcohol seeking. J Neurosci 36:11716-11726.

Qi K, Wei C, Li Y, Sui N (2013) Orexin receptors within the nucleus ac- 
cumbens shell mediate the stress but not drug priming-induced reinstatement of morphine conditioned place preference. Front Behav Neurosci 7:144.

Sakurai T, Amemiya A, Ishii M, Matsuzaki I, Chemelli RM, Tanaka H, Williams SC, Richardson JA, Kozlowski GP, Wilson S, Arch JR, Buckingham RE, Haynes AC, Carr SA, Annan RS, McNulty DE, Liu WS, Terrett JA, Elshourbagy NA, Bergsma DJ, Yanagisawa M (1998a) Orexins and orexin receptors: a family of hypothalamic neuropeptides and G protein-coupled receptors that regulate feeding behavior. Cell 92:573-585.

Sakurai T, Amemiya A, Ishii M, Matsuzaki I, Chemelli RM, Tanaka H, Williams SC, Richarson JA, Kozlowski GP, Wilson S, Arch JR, Buckingham RE, Haynes AC, Carr SA, Annan RS, McNulty DE, Liu WS, Terrett JA, Elshourbagy NA, Bergsma DJ, Yanagisawa M (1998b) Orexins and orexin receptors: a family of hypothalamic neuropeptides and $\mathrm{G}$ proteincoupled receptors that regulate feeding behavior. Cell 92:1.

Sharf R, Guarnieri DJ, Taylor JR, DiLeone RJ (2010) Orexin mediates morphine place preference, but not morphine-induced hyperactivity or sensitization. Brain Res 1317:24-32.

Smith RJ, Aston-Jones G (2012) Orexin / hypocretin 1 receptor antagonist reduces heroin self-administration and cue-induced heroin seeking. Eur J Neurosci 35:798-804.

Smith RJ, See RE, Aston-Jones G (2009) Orexin/hypocretin signaling at the orexin 1 receptor regulates cue-elicited cocaine-seeking. Eur J Neurosci 30:493-503.

Swerdlow NR, Swanson LW, Koob GF (1984) Electrolytic lesions of the substantia innominata and lateral preoptic area attenuate the 'supersensitive' locomotor response to apomorphine resulting from denervation of the nucleus accumbens. Brain Res 306:141-148.

Tsujino N, Sakurai T (2013) Role of orexin in modulating arousal, feeding, and motivation. Front Behav Neurosci 7:28.

Volkow ND, Collins FS (2017) The role of science in addressing the opioid crisis. N Engl J Med 377:391-394.

Williams SF, Herberg LJ (1987) Motivational vs. motor effects of striatal and pallidal gabergic projections to subthalamic and entopeduncular nuclei, ventromedial thalamus, and ventral globus pallidus. Pharmacol Biochem Behav 26:49-55.

Zacny JP, Galinkin JL (1999) Psychotropic drugs used in anesthesia practice: abuse liability and epidemiology of abuse. Anesthesiology 90:269-288 